\title{
Deep Conversion of Carbon Monoxide to Hydrogen and Formation of Acetate by the Anaerobic Thermophile Carboxydothermus hydrogenoformans
}

\author{
Anne M. Henstra ${ }^{1,2}$ and Alfons J. M. Stams ${ }^{2}$ \\ ${ }^{1}$ Centre for Biomolecular Sciences, University of Nottingham, University Park, NG7 2RD Nottingham, UK \\ ${ }^{2}$ Laboratory of Microbiology, Wageningen University, Dreijenplein 10, 6703 HB Wageningen, The Netherlands
}

Correspondence should be addressed to Anne M. Henstra, am.henstra@nottingham.ac.uk

Received 15 March 2011; Accepted 30 April 2011

Academic Editor: L. Chistoserdova

Copyright (C) 2011 A. M. Henstra and A. J. M. Stams. This is an open access article distributed under the Creative Commons Attribution License, which permits unrestricted use, distribution, and reproduction in any medium, provided the original work is properly cited.

\begin{abstract}
Carboxydothermus hydrogenoformans is a thermophilic strictly anaerobic bacterium that catalyses the water gas shift reaction, the conversion of carbon monoxide with water to molecular hydrogen and carbon dioxide. The thermodynamically favorable growth temperature, compared to existing industrial catalytic processes, makes this organism an interesting alternative for production of cheap hydrogen gas suitable to fuel CO-sensitive fuel cells in a future hydrogen economy, provided sufficiently low levels of CO are reached. Here we study $\mathrm{CO}$ conversion and final $\mathrm{CO}$ levels in cultures of $C$. hydrogenoformans grown in batch cultures that were started with a $100 \% \mathrm{CO}$ gas phase with and without removal of formed $\mathrm{CO}_{2}$. Final CO levels were 117 ppm without $\mathrm{CO}_{2}$ removal and below $2 \mathrm{ppm}$ with $\mathrm{CO}_{2}$ removal. The Gibbs free energy change calculated with measured end concentrations and the detection of acetate suggest that $C$. hydrogenoformans shifted from a hydrogenogenic to an acetogenic metabolism.
\end{abstract}

\section{Introduction}

Carboxydothermus hydrogenoformans is a strictly anaerobic carboxydotrophic hydrogenogenic thermophilic bacterium [1] that conserves energy for growth by performing the water gas shift reaction, the conversion of carbon monoxide with water to hydrogen and carbon dioxide (reaction (1)). The standard Gibbs free energy change of the reaction per mol of $\mathrm{CO}$ is relatively small, $-20 \mathrm{~kJ} \mathrm{~mol}^{-1}$. Production of acetate from $\mathrm{CO}$ (reaction (2)) or from $\mathrm{H}_{2}$ and $\mathrm{CO}_{2}$ (reaction (3)) is not reported for $C$. hydrogenoformans, despite the presence of the required genes in the genome of $C$. hydrogenoformans [2]

$$
\begin{gathered}
\mathrm{CO}+\mathrm{H}_{2} \mathrm{O} \longrightarrow \mathrm{CO}_{2}+\mathrm{H}_{2} \\
4 \mathrm{CO}+2 \mathrm{H}_{2} \mathrm{O} \longrightarrow 2 \mathrm{CO}_{2}+\mathrm{CH}_{3} \mathrm{COOH} \\
4 \mathrm{H}_{2}+2 \mathrm{CO}_{2} \longrightarrow \mathrm{CH}_{3} \mathrm{COOH}
\end{gathered}
$$

The water gas shift reaction is applied in industry for production of relative cheap hydrogen gas from synthesis gas. Synthesis gas is a mixture of mainly $\mathrm{H}_{2}, \mathrm{CO}$, and $\mathrm{CO}_{2}$ which is produced by partial oxidation or autothermal reforming of hydrocarbon-rich sources such as fossil fuels, domestic and agricultural wastes, and other biomass sources [3-5]. Water-gas shift catalysis is applied in successive high and low temperature steps at 400 and $200^{\circ} \mathrm{C}$ to convert the bulk of CO to final concentrations of not below $1000 \mathrm{ppm}$. Low-temperature fuel cells are sensitive to $\mathrm{CO}$ and require $\mathrm{CO}$ levels of below $10 \mathrm{ppm}$ or of a few hundred ppm for novel types that apply improved membranes [6]. Hydrogen gas derived from synthesis gas, while relatively cheap, is therefore not suitable for these types of fuel cells. Highly desired is a water-gas shift process capable of removing $\mathrm{CO}$ from synthesis gas to levels below $10 \mathrm{ppm}$ in a single step.

Synthesis gas is also of interest as source for tentative biotechnological processes. Several anaerobic microorganisms 
TABLE 1: Observed partial pressures and the calculated Gibbs free energy change of CO conversion by C. hydrogenoformans in batch culture.

\begin{tabular}{|c|c|c|c|c|c|c|c|}
\hline Culture & $t(\mathrm{~h})$ & $\mathrm{H}_{2}(\mathrm{~Pa})$ & $\mathrm{CO}(\mathrm{Pa})$ & $\mathrm{CO}_{2}(\mathrm{~Pa})$ & Acetate $(\mathrm{mM})$ & $\Delta G_{\mathrm{RI}}^{(\mathrm{a})}$ & $\Delta G_{\mathrm{R} 2}{ }^{(\mathrm{a})}$ \\
\hline \multirow{3}{*}{$-\mathrm{CO}_{2}$ trap } & 0.5 & $6.0 \cdot 10^{2}$ & $2.4 \cdot 10^{5}$ & $1.1 \cdot 10^{3}$ & ${\underline{0.2^{(b)}}}^{(\mathrm{s})}$ & -53 & -52 \\
\hline & 9.5 & $2.0 \cdot 10^{5}$ & $1.8 \cdot 10^{4}$ & $1.3 \cdot 10^{5}$ & & -16 & \\
\hline & 55 & $2.0 \cdot 10^{5}$ & $3.9 \cdot 10^{1}$ & $1.3 \cdot 10^{5}$ & 3.8 & +1 & -18 \\
\hline \multirow{3}{*}{$+\mathrm{CO}_{2}$ trap } & 0.5 & $2.2 \cdot 10^{2}$ & $2.6 \cdot 10^{5}$ & $8.4 \cdot 10^{2}$ & 0.2 & -57 & -52 \\
\hline & 12.5 & $2.0 \cdot 10^{5}$ & $1.4 \cdot 10^{4}$ & $1.2 \cdot 10^{4}$ & & -22 & \\
\hline & 55 & $2.1 \cdot 10^{5}$ & $\underline{0.4 \cdot 10^{0}}$ & $\underline{3.5 \cdot 10^{2}}$ & $\underline{0.2}$ & -3 & -16 \\
\hline
\end{tabular}

${ }^{(a)} \Delta G_{\mathrm{R} 1}$ and $\Delta G_{\mathrm{R} 2}$ : Gibbs free energy change ( $\mathrm{kJ} / \mathrm{mol} \mathrm{CO}$ ) for reaction (1) and reaction (2), respectively, at $70^{\circ} \mathrm{C}[10]$.

(b) Underlined: detection limits that were used in calculation of free energy.

are known that can convert the synthesis gas constituents ( $\mathrm{CO}$ and $\mathrm{H}_{2}+\mathrm{CO}_{2}$ ) into valuable products, for example, methane, ethanol, butanol, and polyhydroxyalkanoates, in what is called synthesis gas fermentation [7, 8]. More microorganisms exist that produce these compounds with only $\mathrm{H}_{2}+\mathrm{CO}_{2}$, but these are often sensitive to $\mathrm{CO}$.

Biotechnological application of microorganisms like $C$. hydrogenoformans to produce a hydrogen gas with minimal $\mathrm{CO}$ is thus interesting. They bring the advantage that they operate at lower temperatures than existing watergas shift catalyst, which is thermodynamically favorable for the removal of $\mathrm{CO}$. Here, we describe the results of a study on $\mathrm{CO}$ conversion by and final $\mathrm{CO}$ thresholds of $C$. hydrogenoformans metabolism in batch culture. Removal of $\mathrm{CO}_{2}$ is studied as it is a means to acquire lower final CO thresholds. The effect on metabolism in relation to minimal free energy change is discussed.

\section{Materials and Methods}

C. hydrogenoformans (DSM6008) was obtained from the German Culture Collection (DSMZ, Braunschweig) and cultured in $585 \mathrm{~mL}$ serum-stoppered bottles in a medium buffered with $200 \mathrm{~mL}$ MOPS [9] and a 100\% CO gas phase at $65^{\circ} \mathrm{C}$ and $200 \mathrm{rpm}$ ( 1 " stroke Innova 44 incubator, New Brunswick Scientific). Bottles contained a glass reaction tube with either $5 \mathrm{~mL}$ water as control or $5 \mathrm{~mL} 10 \mathrm{M} \mathrm{NaOH}$ to serve as $\mathrm{CO}_{2}$ trap. $\mathrm{CO}, \mathrm{H}_{2}, \mathrm{CO}_{2}$, acetate, and growth of $C$. hydrogenoformans were analysed as described [9]. Gas and liquid samples were taken with intervals of 180 minutes until $15.5 \mathrm{~h}$. Trace levels of CO $\left(P_{\mathrm{CO}}<800 \mathrm{~Pa}\right)$ were analysed on a GC2010 fitted with MTN-1 methanizer (Shimadzu, Japan) and FID by injecting gas samples of $100 \mu \mathrm{L}$ with a glass gastight syringe that were allowed to equilibrate with atmospheric pressure just before injection into the GC. The Gibbs free energy changes were calculated with observed gas partial pressures and tabulated data for $70^{\circ} \mathrm{C}$ [10]. Partial pressures of $\mathrm{CO}_{2}$ and $\mathrm{H}_{2}$ at $15.5 \mathrm{~h}$ were used for calculation of $\Delta G$ of later samples where only trace CO was measured, unless stated otherwise.

\section{Results and Discussion}

The metabolic capacity of C. hydrogenoformans cultures to achieve low $\mathrm{CO}$ concentrations by $\mathrm{CO}$ conversion to $\mathrm{H}_{2}$ and the effect of $\mathrm{CO}_{2}$ removal were studied. C. hydrogenoformans was grown in batch cultures with a $\mathrm{CO}$ gas phase. Incubations were done with and without a $\mathrm{CO}_{2}$ trap. The optical density and $\mathrm{CO}, \mathrm{H}_{2}$, and $\mathrm{CO}_{2}$ concentrations were measured over time (Figure 1). The final $\mathrm{pH}$ and acetate concentrations were also measured. With measured concentrations, the Gibbs free energy changes for reaction (1) and (2) were calculated (Table 1).

The cultures with $\mathrm{CO}_{2}$ trap showed very similar $\mathrm{CO}$ uptake rates and $\mathrm{H}_{2}$ production rates compared to cultures without trap, however, with a clearly longer lag phase and lower final OD than cultures without trap. Likely, the removal of $\mathrm{CO}_{2}$ affects growth, as it is an intermediate in the carbon assimilation by $C$. hydrogenoformans through the acetyl-CoA pathway. Additionally, the $\mathrm{CO}_{2}$ trap, which is an alkaline solution, could trap the acid gas, $\mathrm{H}_{2} \mathrm{~S}$, which serves as source of sulfur and the low redox potential needed for growth of $C$. hydrogenoformans. Once CO conversion in cultures with $\mathrm{CO}_{2}$ trap reached comparable rates to cultures without trap, $\mathrm{CO}_{2}$ started to accumulate until most $\mathrm{CO}$ was consumed. Thereafter $\mathrm{CO}_{2}$ dropped to end point concentrations below the detection limits $(<350 \mathrm{kPa})$. Final $\mathrm{CO}$ levels in cultures without $\mathrm{CO}_{2}$ trap were $117 \mathrm{ppm}$, while in cultures with $\mathrm{CO}_{2}$ trap the $\mathrm{CO}$ levels had dropped below the detection limit of $2 \mathrm{ppm}$.

With measured concentrations, using detection limits where concentrations could not be measured, the Gibbs free energy change was calculated for reactions (1) and (2) (Table 1). For reaction (1), the conversion of $\mathrm{CO}$ with water to $\mathrm{CO}_{2}$ and $\mathrm{H}_{2}, \Delta G$ were +1.4 and $-3 \mathrm{~kJ} / \mathrm{mol} \mathrm{CO}$ for cultures without and with $\mathrm{CO}_{2}$ trap, respectively. These values are closer to thermodynamic equilibrium $(\Delta G=0)$ than can be expected based on minimal biological energy quantum theory that takes the Gibbs free energy to translocate one proton over the cytoplasmic membrane as minimum, which was assumed $-20 \mathrm{~kJ} \mathrm{~mol}^{-1}[11]$, even when a degree of variability is allowed for the minimal biological energy quantum [12]. Instead of reaction (1), the conversion of $\mathrm{CO}$ to $\mathrm{H}_{2}$, another metabolic reaction that causes the removal of $\mathrm{CO}$ in later stages of culture. Acetate was detected in cultures without $\mathrm{CO}_{2}$ trap, which suggests $C$. hydrogenoformans shifted from reaction (1) to reaction (2) during cultivation. The $\Delta G$ for reaction (2) with average concentration of $3.8 \mathrm{mM}$ acetate was $-18 \mathrm{~kJ} \mathrm{~mol}^{-1}$ for cultures without $\mathrm{CO}_{2}$ trap, which is much closer to theoretical $-20 \mathrm{~kJ} \mathrm{~mol}^{-1}$ of the minimal biological energy quantum. However, in cultures with $\mathrm{CO}_{2}$ 


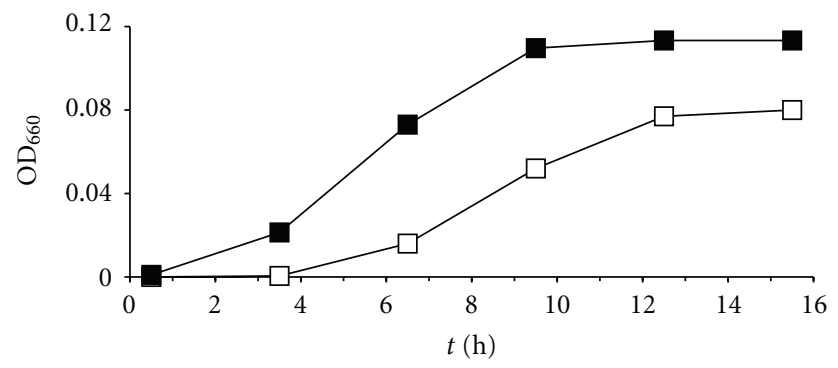

(a)

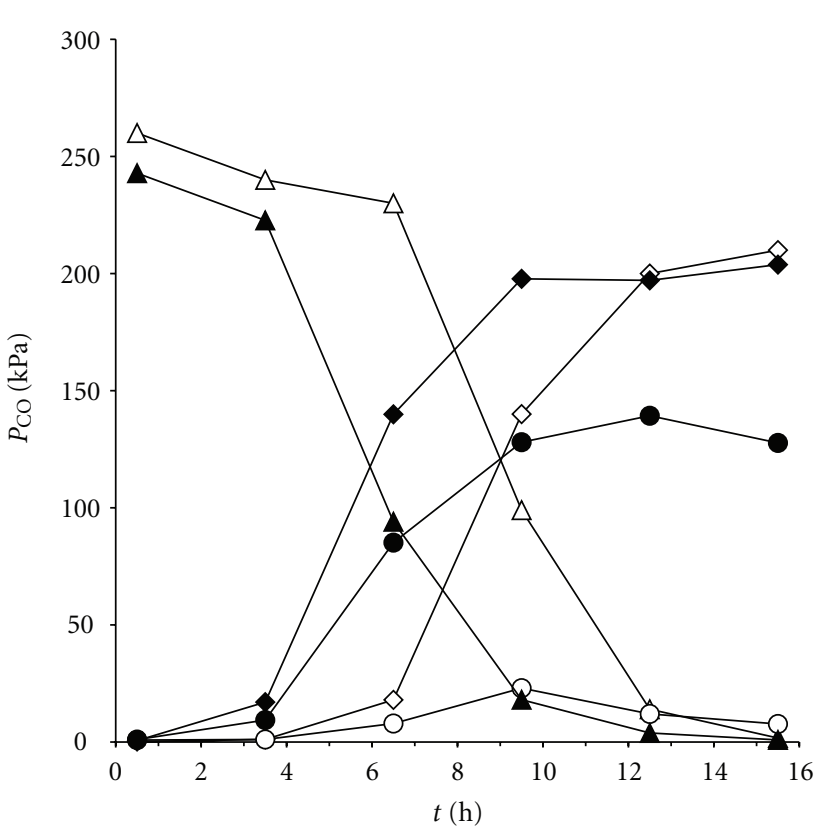

(b)

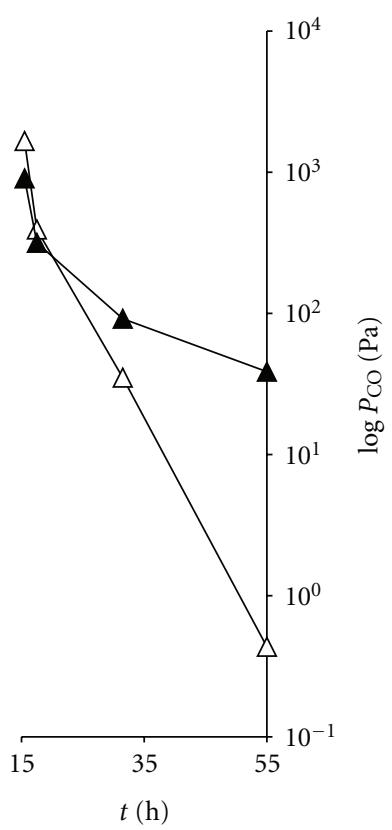

(c)

Figure 1: Final CO levels of the hydrogenogenic $\mathrm{CO}$ metabolism of $C$. hydrogenoformans was studied batch cultures, with $\mathrm{CO}_{2}$ trap and without $\mathrm{CO}_{2}$ trap (open versus closed symbols, resp.), in triplicate. Optical density of cultures ((a), square symbols), and partial pressures of $\mathrm{CO}$ ((b), triangles), $\mathrm{H}_{2}$ (diamonds), and $\mathrm{CO}_{2}$ (circles) were monitored over time and plotted on a linear axis. Trace levels of $\mathrm{CO}$ (c) were plotted on a logarithmic axis from $15.5 \mathrm{~h}$ onward.

trap, acetate was not detected. The detection limit for acetate was $0.2 \mathrm{mM}$. It is possible that enough $\mathrm{CO}$ or $\mathrm{CO}_{2}$ was not available to produce more acetate than the detection limit in cultures with $\mathrm{CO}_{2}$ trap. With $0.2 \mathrm{mM}$ acetate, a $\Delta G_{\mathrm{R} 2}$ of $-16 \mathrm{~kJ} \mathrm{~mol}^{-1} \mathrm{CO}$ was calculated which is more in accordance with the minimal biological energy quantum.

\section{Conclusion}

Batch cultivation of $C$. hydrogenoformans with $\mathrm{CO}$ resulted in final $\mathrm{CO}$ concentrations of $117 \mathrm{ppm}$. With removal of $\mathrm{CO}_{2}$ during cultivation, even lower CO concentrations of below $2 \mathrm{ppm}$ were reached. The low CO levels in the produced hydrogen-rich gas make the gas suitable for application in $\mathrm{CO}$-sensitive processes. Low-temperature fuel cells require $\mathrm{CO}$ to be present below $10 \mathrm{ppm}$ [8]. Improved fuel cell membranes allow several hundred ppm $[13,14]$. While the bulk of $\mathrm{CO}$ was converted to $\mathrm{H}_{2}$ by $C$. hydrogenoformans, it is likely that metabolism shifted to production of acetate from $\mathrm{CO}$ in final stages of incubation. Production of acetate by C. hydrogenoformans was not shown before. To apply such a biological catalyst, further research is needed on kinetic aspects, mainly relating to mass transfer at the gas-liquidmicrobe interfaces.

\section{Acknowledgments}

This research was financed by the Technology Foundation (STW), Applied Science Division of the Netherlands Organisation for Scientific Research (NWO), with the Project no. STW-WBC5280 and additional support from Paques B.V. (Balk, The Netherlands) and Shell Global Solutions (Amsterdam, The Netherlands). 


\section{References}

[1] V. Svetlitchnyi, C. Peschel, G. Acker, and O. Meyer, "Two membrane-associated NiFeS-carbon monoxide dehydrogenases from the anaerobic carbon-monoxide-utilizing eubacterium Carboxydothermus hydrogenoformans," Journal of Bacteriology, vol. 183, no. 17, pp. 5134-5144, 2001.

[2] M. Wu, Q. Ren, A. S. Durkin et al., "Life in hot carbon monoxide: the complete genome sequence of Carboxydothermus hydrogenoformans Z-2901," PLoS Genetics, vol. 1, no. 5, pp. 563-574, 2005.

[3] J. R. Rostrup-Nielsen, "Syngas in perspective," Catalysis Today, vol. 71, no. 3-4, pp. 243-247, 2002.

[4] N. Piatkowski and A. Steinfeld, "Reaction kinetics of the combined pyrolysis and steam-gasification of carbonaceous waste materials," Fuel, vol. 89, no. 5, pp. 1133-1140, 2010.

[5] M. M. Yung, W. S. Jablonski, and K. A. Magrini-Bair, "Review of catalytic conditioning of biomass-derived syngas," Energy and Fuels, vol. 23, no. 4, pp. 1874-1887, 2009.

[6] C. Song, "Fuel processing for low-temperature and hightemperature fuel cells: challenges, and opportunities for sustainable development in the 21st century," Catalysis Today, vol. 77, no. 1-2, pp. 17-49, 2002.

[7] Y. S. Do, J. Smeenk, K. M. Broer et al., "Growth of Rhodospirillum rubrum on synthesis gas: conversion of $\mathrm{CO}$ to $\mathrm{H}_{2}$ and poly- $\beta$-hydroxyalkanoate," Biotechnology and Bioengineering, vol. 97, no. 2, pp. 279-286, 2007.

[8] A. M. Henstra, J. Sipma, A. Rinzema, and A. J. M. Stams, "Microbiology of synthesis gas fermentation for biofuel production," Current Opinion in Biotechnology, vol. 18, no. 3, pp. 200-206, 2007.

[9] A. M. Henstra and A. J. M. Stams, "Novel physiological features of Carboxydothermus hydrogenoformans and Thermoterrabacterium ferrireducens," Applied and Environmental Microbiology, vol. 70, no. 12, pp. 7236-7240, 2004.

[10] J. P. Amend and E. L. Shock, "Energetics of overall metabolic reactions of thermophilic and hyperthermophilic Archaea and Bacteria," FEMS Microbiology Reviews, vol. 25, no. 2, pp. 175243, 2001.

[11] B. Schink, "Energetics of syntrophic cooperation in methanogenic degradation," Microbiology and Molecular Biology Reviews, vol. 61, no. 2, pp. 262-280, 1997.

[12] T. M. Hoehler, M. J. Alperin, D. B. Albert, and C. S. Martens, "Apparent minimum free energy requirements for methanogenic Archaea and sulfate-reducing bacteria in an anoxic marine sediment," FEMS Microbiology Ecology, vol. 38, no. 1 , pp. 33-41, 2001.

[13] A. T. Haug, R. E. White, J. W. Weidner, and W. Huang, "Development of a novel $\mathrm{CO}$ tolerant proton exchange membrane fuel cell anode," Journal of the Electrochemical Society, vol. 149, no. 7, pp. A862-A867, 2002.

[14] D. C. Papageorgopoulos, M. Keijzer, and F. A. de Bruijn, "The inclusion of $\mathrm{Mo}, \mathrm{Nb}$ and $\mathrm{Ta}$ in Pt and PtRu carbon supported electrocatalysts in the quest for improved CO tolerant PEMFC anodes," Electrochimica Acta, vol. 48, no. 2, pp. 197-204, 2002. 

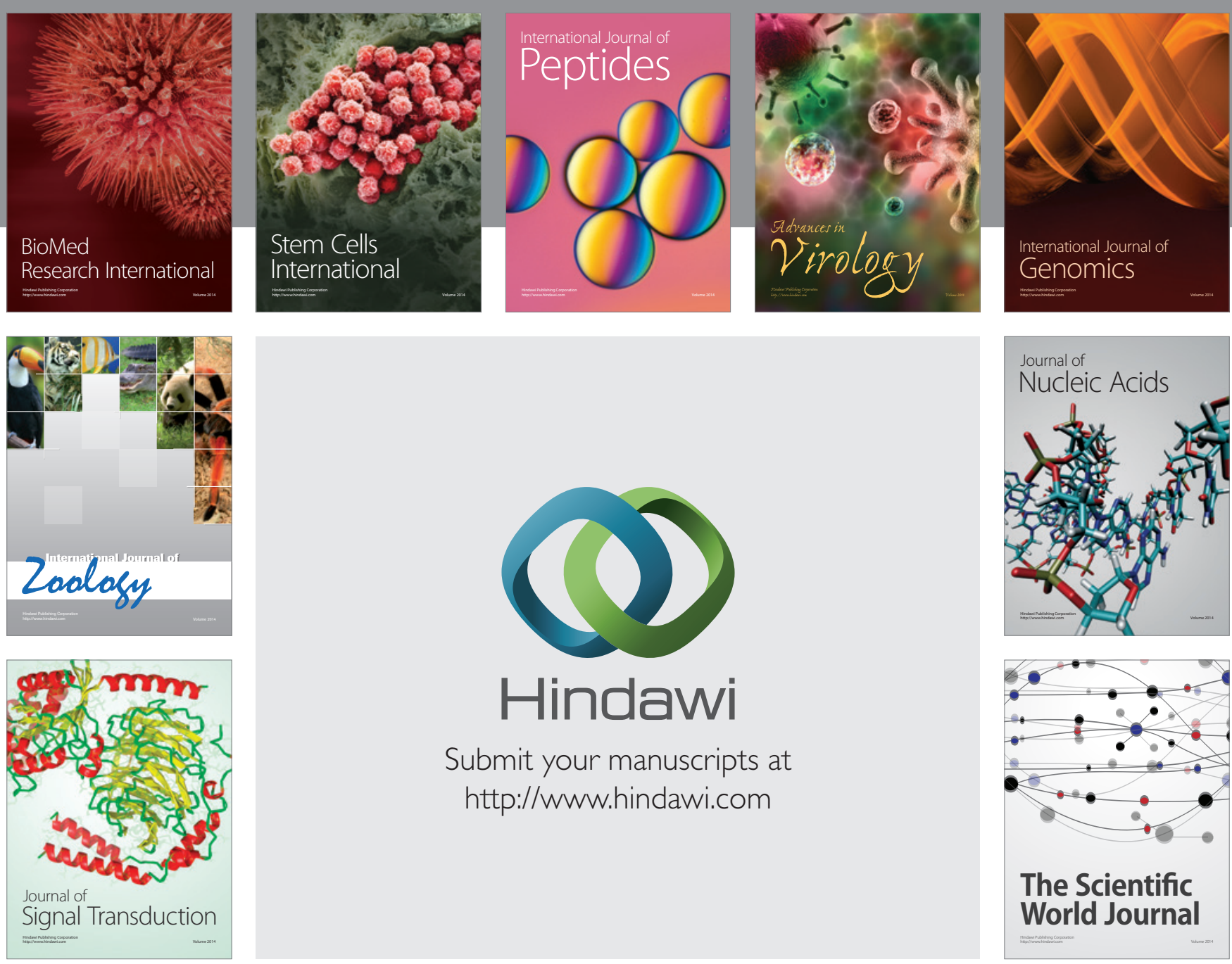

Submit your manuscripts at

http://www.hindawi.com
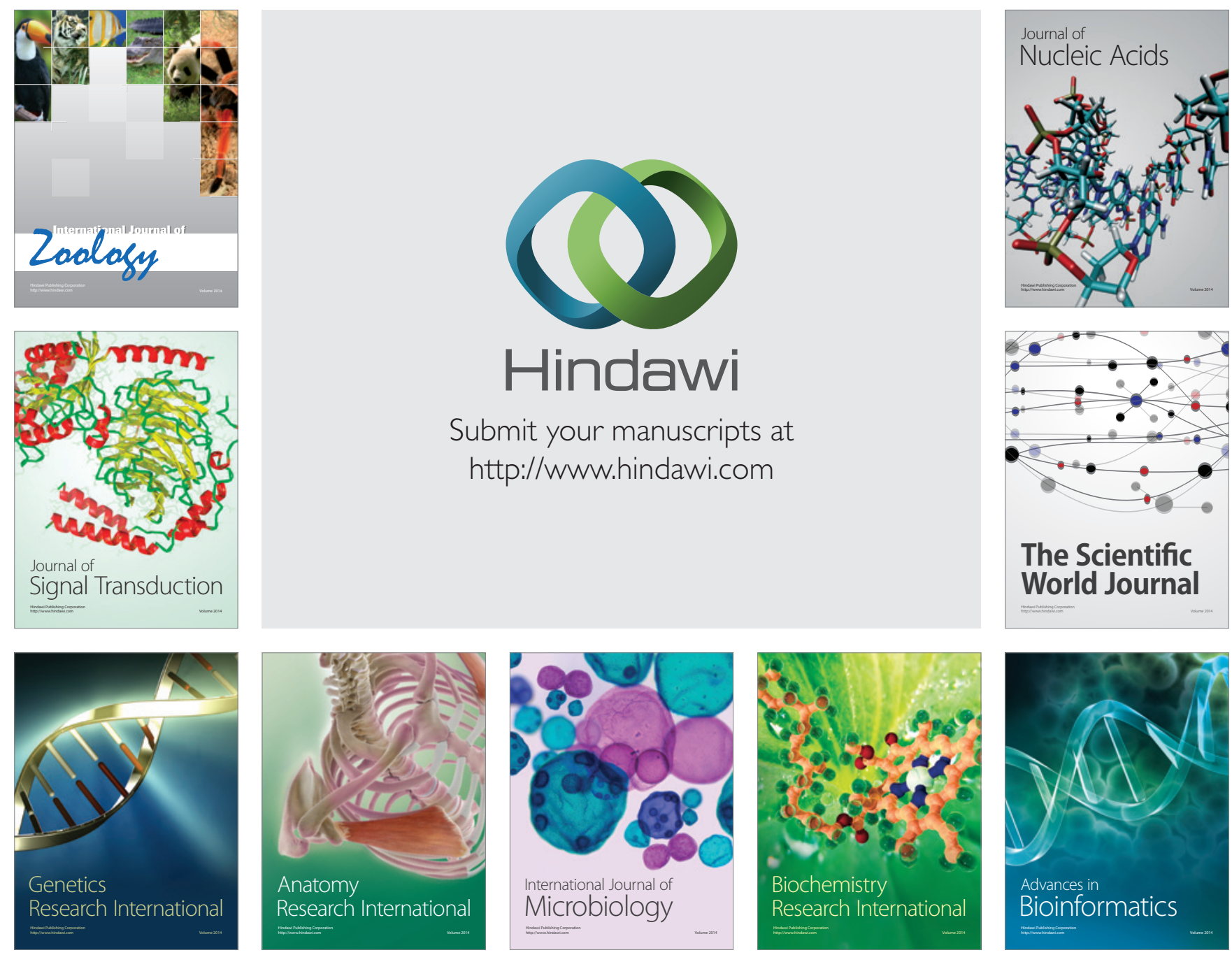

The Scientific World Journal
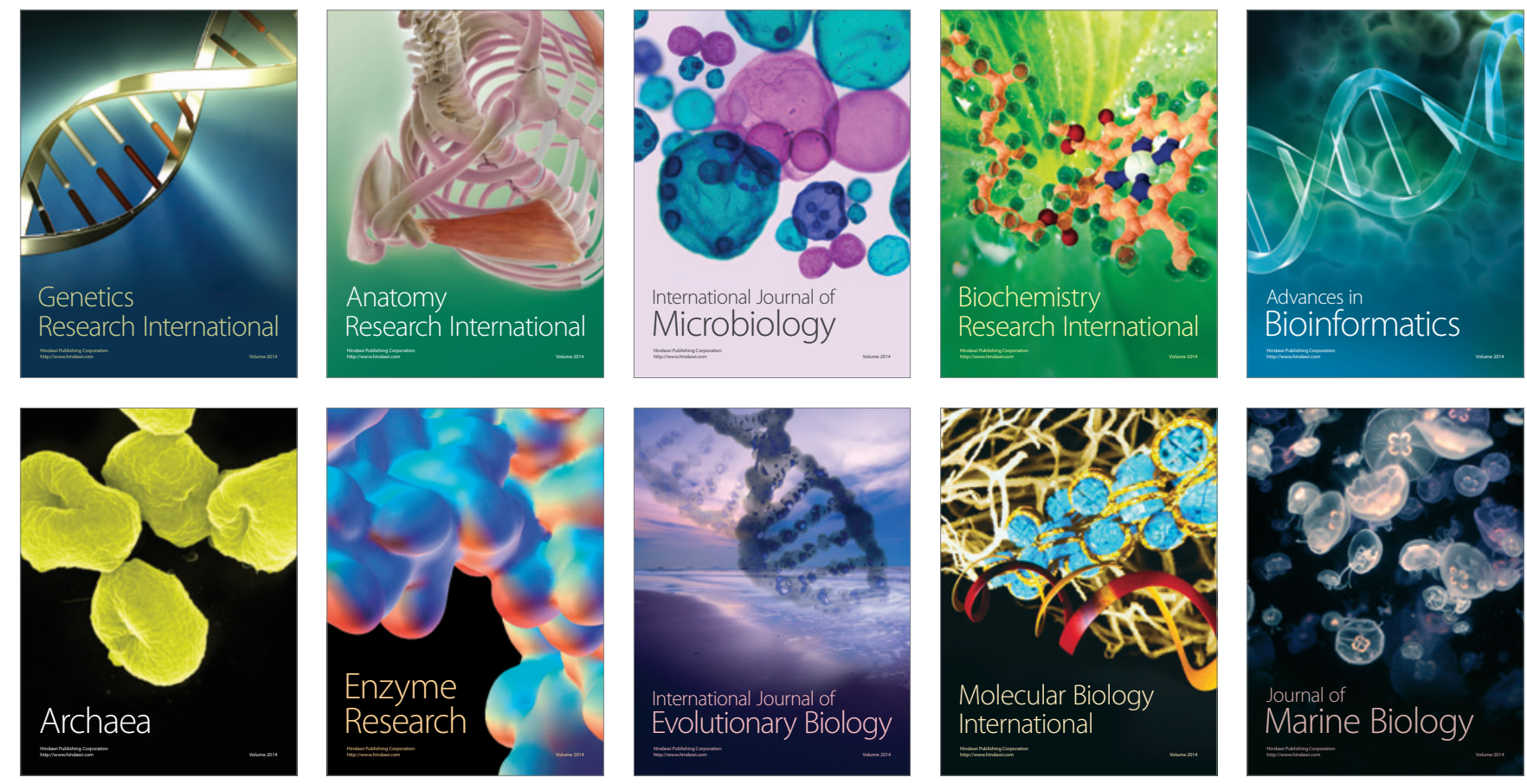